DOI: 10.15393/j9.art.2012.357

Марта Лукашевич

кандидат филологических наук, научный сотрудник Варшавского университета

(Варшава, Польша)

marta.lukaszewicz@uw.edu.pl

\title{
БИБЛИЯ В ХУДОЖЕСТВЕННОМ МИРЕ РАССКАЗА Н. С. ЛЕСКОВА «ОДНОДУМ»
}

Аннотация: Многочисленные факты свидетельствуют о том, какое большое значение придавал Священному Писанию Николай Лесков. Вопросам доступности Библии посвящены его первые газетные заметки; в качестве издателя и редактора он сделал многое для распространения знания Писания среди русского народа, видя в этом основу нравственного воспитания человека. Также в художественных произведениях Лескова можно найти библейские цитаты, реминисценции, мотивы и образы. Цель настоящей статьи состоит в определении места и значения Библии в структуре одного из рассказов писателя - «Однодум», созданного в 1879 г. Он выделяется на фоне других произведений более акцентированной связью со Священным Писанием, что обнаруживается на уровне как формы, так и содержания. В статье проанализировано влияние Священного Писания на формирование главного героя, Александра Рыжова, и особенности его поведения, а также на его восприятие обществом, указан также возможный исторический контекст представленных в рассказе дискуссий о значении Библии в жизни православного верующего, а именно - период споров вокруг Российского Библейского общества и перевода Евангелия на русский язык. Отмечено, что черты Рыжова, особенно его репутация „чудака” и „сомнительного в вере”, роднят его с другими лесковскими праведниками, благодаря чему он приобретает также вневременное значение.

Ключевые слова: Н. С. Лесков, Библия, пророк, юродивый, Российское Библейское Общество

$\mathrm{M}$ Ногочисленные факты свидетельствуют о значении, которое придавал Священному Писанию Николай Лесков. Писатель неоднократно сожалел о плохом знании Библии в русском обществе $^{1}$, отмечая при этом заметную среди благочестивых людей потребность читать и понимать эту книгу. В двух первых своих публикациях - небольших газетных заметках, напечатанных в «Указателе экономическом» (№ 181 за 1860 г.) и «Санкт-Петербургских ведомостях» (№ 135 за 1860 г.), он выражал возмущение завышенными ценами продажи Евангелия на русском языке в книжных лавках Киева, отмечая при этом, с каким нетерпением ждали этого издания верующие люди ${ }^{2}$.

Также в качестве издателя и редактора Лесков сделал многое для распространения знания Библии среди русского народа. Например, в 1876 г. он подготовил для журнала «Русский рабочий» переложение отрывка из 3-й книги Царств, повествующего о посещении пророком Ильей вдовы в Сарепте Сидонской (3 Цар 17:8-24)후 в 1877 г. переиздал сборник нравственных поучений, основанных на Священном Писании «Зеркало жизни истинного ученика Христова» ${ }^{4}$ в 
1879 г. издал «Указку к книге Нового Завета» ${ }^{5}$ и т. п. Об этом малоизвестном аспекте творчества Лескова более подробно пишет Инес Мюллер де Морог в своей очень содержательной статье на французском языке «Н. С. Лесков - религиозный пропагандист и критик нравоучительной литературы» [8].

Внимание вопросу о роли Библии в нравственном воспитании человека уделял Лесков также в своих письмах, подчеркивая жизненную ценность евангельского учения ${ }^{6}$, значение "хорошо прочитанного Евангелия» в собственном становлении ${ }^{7}$ или лаконично указывая пасынку Борису Бубнову: «Библию прочесть надо» ${ }^{8}$. Наконец, его публицистические и художественные произведения полны как прямых отсылок к Священному Писанию, так и библейских цитат, реминисценций, образов и мотивов ${ }^{9}$.

Созданный в 1879 г. рассказ «Однодум» выделяется на этом фоне ключевым местом, которое занимает в нем Библия. Оно заметно уже на текстовом уровне: первая глава, повествующая о детстве и отрочестве главного героя Александра Рыжова, заканчивается абзацем в одно предложение:

Книга эта (которую Рыжов всегда носил с собой. - M. Л.) была Библия ${ }^{10}$.

Таким образом, уже первое упоминание о Священном Писании выдвигает его на акцентированное место, привлекая к нему внимание читателя и предвещая его особое значение в структуре рассказа.

Как большинство произведений Лескова, «Однодум» насыщен цитатами и реминисценциями, в том числе библейскими. Хотя последних не так много в рассказе, тем не менее и здесь можно говорить об их особом выделении, которое совершается посредством включения в текст второй главы пространного фрагмента приводимого неточно начала книги пророка Исаии в славянском переводе (Ис. 1:3-24). Объем цитируемого текста (почти полстраницы) указывает, по-видимому, как на особое место Библии в структуре произведения, так и на значение для главного героя именно данного отрывка, обличающего "князей» и «крепких» мира сего за их любовь к подаркам и взяткам, т. е. созвучного убеждениям самого Рыжова (или, точнее говоря, определяющего эти убеждения).

Текстовому выделению Библии соответствует подчеркивание рассказчиком ее значения для формирования героя, его характера, мировоззрения, морали: «...книга, имевшая на него неодолимое влияние» (7); «он приобрел в ней большие и твердые познания, легшие в основу всей его последующей оригинальной жизни» (8). Такую же функцию имеет повторяющийся по отношению к герою эпитет «библейский»: «библей ские воззрения» (8), «библейский чудак» (17), «библейский социалист» (32) и т. п. Что важно, также для других действующих лиц хорошее знание Библии является объяснением всех странностей героя. Так, в разго воре с городничим протопоп сообщает о «вредной фантазии» Рыжова 
- Библии начитался.

$<\ldots>$

- Экий дурак! Что же теперь с ним сделать?

- Ничего не сделаешь: он уже очень далеко начитан (15).

Также для городского головы упоминание о чтении Священного Писания все делает понятным:

- Отчего же так всем нельзя, а он обходится?

- Библии начитался (29).

Сам Рыжов тоже осознает, что́ является основой его нравственных установок, обосновывая свои поступки ссылками на авторитет Бога и его Слова:

...он... объявил, что ему по касающемуся ни от кого ничего не следует, потому что... «мзду брать Бог запрещает» (12); Ложь заповедью запрещена - я лгать не стану (31); - Гм, гм! Вы ниоткуда это учение не почерпаете? - Из Священного Писания и моей совести (32).

Установив принципиальное значение Библии для главного героя, перейдем к вопросу о характере и результатах ее влияния. Об этом со общает непосредственно рассказчик:

Рыжов... знал наизусть все писания многих пророков и особенно любил Исаию, широкое боговедение которого отвечало его душевной настроенности и составляло весь его катехизис и все богословие (8).

Заявление о ветхозаветных, пророческих основах мировосприятия героя находит затем многократное подтверждение в тексте, когда именно большой отрывок из книги пророка Исаии выкрикивает Рыжов у дуба на болоте, когда упоминаются «виденные Иезекиилем „сухие кости”» (9) или когда, наконец, деятельность Рыжова нарямую сравнивается со служением пророка:

Александру-то Афанасьевичу и предстояло... напророчить ему повышение (20); Рыжов... продолжал писать в нем, что изливали его наблюдательность и пророческое вдохновение (33).

Подобно многим ветхозаветным пророкам, герой считает своим призванием не только жить согласно принятым им самим библейским правилам, но и наставлять и обличать других. Наиболее заметным это становится в отношениях с Ланским, которому Рыжов повелевает вести себя в храме более смиренно, а потом еще и советует читать Библию.

Как отмечает Джулия Алиссандратос, в рассказе «Однодум» Лесков использовал ряд мотивов, характерных для житий святых. Одним из них является выделение особого этапа уединения, духовной подготовки к последующему служению $[6,420]$. Этот мотив присутствует, например, в житии преп. Антония Великого или преп. Сергия Радонежского. Восходит же он к Библии: в пустыню удалился на сорок дней Иисус Христос (Мф. 4:1-11; Мк. 1:12-13; Лк. 4:1-13), пребывал там «до дня явления своего Израилю» Иоанн Предтеча (Лк. 1:80). В Ветхом Завете через период уединения прошли многие 
пророки: Моисей (пасший овец своего тестя Иофора «далеко в пустыне» (Исх. 3:1)), Давид (тоже бывший пастухом овец (1Цар. 16:11)), Илья (пребывавший у потока Хорафа, где его кормили вороны (3Цар. 17:5-6), Амос (еще один пастух овец (Ам. 1:1)). Он предшествовал обычно Божьему посещению и призванию на служение. В «Однодуме» также появляются выражения, уподобляющие ключевые события жизни героя пути Божьего избранника, пророка:

Рыжов... дождался духа (9); он принял это посвящение (9); Развитие Рыжова было уже совершенно закончено, и наступало время деятельности (9).

Следует заметить, что бескомпромиссности Рыжова в применении на деле своих жизненных принципов сопутствует и некоторая узость в понимании библейского текста, отмеченная даже в самом его прозвище Однодум. Именно она, как нам кажется, делает его подчас излишне жестким, как, например, в случае с засоленными подаренной солью груздями, когда Рыжов избил свою жену за нарушение ею запрета принимать какие-либо дары. Таким образом, хотя Рыжов и «до Христа дочитался» (как явствует из разговора протопопа с городничим), он усвоил из Священного Писания прежде всего Ветхий Завет, и именно ветхозаветная праведность, как считает Аллисандратос, легла в основу его нравст венного кодекса $[6,421]$. Евангельскую заповедь о любви к ближнему заменяют герою обостренное чувство справедливости (в том числе социальной) и сострадание к бедным и угнетенным, соединенные с отрицательным отношением к богатым и власть имущим. Такой подход - наиболее ярко представленный в беседе с Ланским на тему введения попенного сбора и податей - опять же сближает Рыжова с ветхозаветными пророками, книги которых содержат резкие обличения в адрес тех, кто притесняет нуждающихся ${ }^{11}$.

Такая узость и даже определенная ущербность библейских воззрений героя обусловливает наличие некоторой иронии и дистанции в отношении к нему автора: «задо́хнувшаяся в тесноте удивительная сила» (9); «загадочный чудак» (16); «упрямец Рыжов» (24). Тем не менее его прямолинейное толкование Библии оценивается выше, чем софистическое отношение к ней протопопа, считающего, что в Священном Писании «кийждо своя отыскать может» (14).

Сосредоточенность Рыжова на Библии и строгое следование выведенным из нее нравственным правилам (центральным из которых становится в рассказе отказ не только брать взятки, но и принимать подарки) снискивают герою среди соседей репутацию «чудака», «дурака» (15), «поврежденного от Библии» (18), но и «еретика» (13), масона («Это новость масонская» - 14), чье православие кажется всем «сомнитель ным» (33) и которого подозревают в принадлежности к какой-то секте (30). Как замечает Джулия Алиссандратос, чтение Библии и серьезное к ней отношение кажутся абсурдом с точки зрения жителей Солигалича $[6,424]$. Добавим, что не 
только абсурдом, но и занятием потенциально опасным, угрожающим отклонением от благочестия и потерей рассудка («в иночестве от нее страсть мечется, а у мирских людей ум мешается» - 29) или выработкой неблагонадежного образа мыслей, «за которые тогда... посылали молиться в Соловецкий монастырь» (19).

Таким образом, значение Библии для православного верующего становится в рассказе предметом художественного обсуждения, которое отражает настороженное и в то же время снисходительное отношение к чтению Библии простого народа («На Руси все православные знают, что кто Библию прочитал и „до Христа дочитался”, с того резонных поступков строго спрашивать нельзя» (15)), а также реальные споры эпохи царствования Александра I и Николая I, т. е. времени, когда происходит действие «Однодума» (в тексте говорится, что Рыжов родился при Екатерине II (5), а фигура губернатора Ланского соответствует исторической личности графа Сергея Степановича Ланского, бывшего костромским губернатором в 18311834 гг.) [1, 407]. Нелишне будет кратко напомнить как сами эти споры, так и их предысторию.

С времен церковной реформы Петра I усилилось влияние на русскую религиозную жизнь протестантизма, с его исключительным авторитетом Священного Писания, которое признавалось единственным источником христианского вероучения. К нему присоединилось также веяние пиетизма - мистического направления внутри лютеранства, пропагандирующего идеи «истинного христианства» и "универсальной церкви», акцентирующего значение личного чтения Библии, как пути к Богу [7, 258]. Именно пиетизм, в соединении с русскими народными сектами, в значительной мере определял духовную атмосферу второго десятилетия царствования Александра I, а также дал толчок к основанию в 1813 г. Российского Библейского Общества и решению переводить Священное Писание на русский язык.

Несмотря на участие в трудах РБО и в самом деле перевода представителей Русской православной церкви, в том числе ректора Санкт-Петербургской духовной академии архимандрита Филарета (Дроздова), будущего митрополита Московского, преобладание мистически эзотерических настроений насторожило некоторых "ревнителей православия» и в результате привело не только к запрещению Общества в 1826 г., приостановлению перевода Библии, но и к сожжению уже напечатанных экземпляров Пятикнижия.

1810-е и 1820-е гг. в России можно считать периодом обострения споров о месте Священного Писания в жизни верующих мирян. С одной стороны, мы имеем позицию пиетистов, чье влияние распространялось на высокопоставленных лиц Российской империи, которые начали читать дома Библию, распространять ее, ссылаться на нее в официальных выступлениях и т. п. [4] Также часть православ- 
ной иерархии принадлежала к горячим сторонникам доступности Библии для всех желающих; например, митр. Филарет утверждал, что «самое желание читать священные книги есть уже залог нравственного улучшения» [4, 171]. Чертой времени стало толкование современных событий сквозь призму библейских слов, в связи с чем особый интерес вызывали ветхозаветные пророческие книги и Апокалипсис. Отражение этих тенденций видно и в рассказе Лескова, где Рыжов в своей тетради, озаглавленной «Однодум», комментирует политические и общественные события в России, предсказывая их последствия, как сам утверждает, на основании Библии.

С другой стороны, засилье западных протестантских проповедников в РБО и частое в то время отрицательное отношение к православным догматам и обрядам со стороны высших чиновников вызвали опасения, что предполагается замена православия некой универсальной библейской религией. Это повлекло за собой подозрительное отношение к самой Библии, которую начали считать книгой опасной - как для общественного порядка, так и для отдельных людей. Так, министр народного просвещения А. С. Шишков утверждал, что чтение Священного Писания может стать причиной возмущений, бунтов, а также ересей и расколов. Как пишет протоиерей Г. Флоровский:

...в то время «самые набожные люди имели несчастную мысль, что от чтения сей священной книги люди с ума сходят». Одно время чтение Библии было формально воспрещено воспитанникам военно-учебных заведений - в предотвращение помешательства, под тем предлогом, что два кадета уже помешались. А многие другие «почитали ее книгою только для Церкви потребной и для попов одних годной» $[4,171]$.

Таким образом, мы видим, что подозрительное отношение жителей Солигалича к «библейскому чудаку» Александру Рыжову и его строгой приверженности к Священному Писанию можно связывать с определенным историческим периодом, хотя, несомненно, не следует все к нему сводить. Сам Лесков указывает на наличие среди простого народа издав на укоренившегося убеждения, что «кто Библию прочитал и „до Христа дочитался”, с того резонных поступков строго спрашивать нельзя» (15). В то же время отверженность и неприятие обществом во все века были уделом тех, кто всерьез принимал библейское учение и выбирал в жизни узкий путь. Наконец, репутация «чудака» и «сомнительного в вере» характерна для большинства героев Лескова, и особенно для его праведников, которых А. А. Горелов назвал «неканоническими святыми» $[1,55]$ (см. также: [5]). На их фоне Александр Рыжов выделяется именно отношением к Библии, и особенно - к Ветхому Завету и его пророческим книгам. Священное Писание занимает в произведении особое место, что проявляется как на формальном, так и на содержательном уровне. 


\section{Примечания}

1 См., напр.: Лесков Н. С. О сводных браках и других немощах // Гражданин. 1875. № 3. С. 73; Лесков Н. С. Письмо Л. И. Веселитской от 2 июля 1893 // Лесков Н. С. Собр. соч.: В 11 т. Т. 11. М., 1957. С. 547.

2 [Лесков Н. С.] <О продаже в Киеве Евангелия> // Указатель экономический. 1860. № 181. Вып. 25. С. 437; Лесков Н. С. Корреспонденция (Письмо г. Лескова) // Санкт-Петербургские ведомости. 1860. № 135.21 июня. С. 699-700.

3 Он же. Пророк Илья у вдовы // Русский рабочий. 1879. № 5. С. 17-18.

4 Он же. Зеркало жизни истинного ученика Христова. СПб., 1877.

5 Он же. Указка к книге Нового Завета. СПб., 1879.

6 Лесков Н. С. Письмо А. С. Суворину от 9 октября 1883 // Лесков Н. С. Собр. соч.: В 11 т. Т. 11. С. 287.

7 Лесков Н. С. Письмо М. А. Протопопову от 23 декабря 1891 // Лесков Н. С. Собр. соч.: В 11 т. Т. 11. С. 509.

8 Лесков Н. С. Письмо Б. М. Бубнову от 21 мая 1892 // Лесков Н. С. Собр. соч.: B 11 т. T. 11. C. 515.

9 Об этом см., напр.: [2], [3].

10 Лесков Н. С. Однодум // Лесков Н. С. Собр. соч.: В 12 т. Т. 2. М., 1989. С. 7. В дальнейшем ссылки на этот источник даются в тексте в скобках с указанием страницы.

11 См., напр.: Ис. 1:16-17, 23; 58:3-7; Ам. 4:1-3; Мих. 2:1-2; 3:1-3.

\section{Список литературы}

1. Горелов А. А. «Праведники» и «праведнический» цикл в творческой эволюции Н. С. Лескова // Лесков и русская литература. М.: Наука, 1988. С. 39-61.

2. Каданер О. В. Библейские мотивы в антинигилистическом романе Н. С. Лескова «На ножах» // Литература и христианство. Белгород: Изд-во БелГУ, 2000. C. $68-69$.

3. Сафран Г. Евангельский подтекст и еврейская тема во «Владычном суде» Н. С. Лескова // Евангельский текст в русской поэзии XVIII-XX веков: цитата, реминисценция, мотив, сюжет, жанр. Вып. 2. Петрозаводск: ПетрГУ, 1998. С. $462-469$.

4. Флоровский Г., прот. Пути русского богословия. Париж: YMCA-PRESS, 1983. 599 c.

5. Хализев В., Майорова О. Лесковская концепция праведничества // В мире Лескова: Сб. ст. М.: Советский писатель, 1983. С. 196-232.

6. Alissandratos J. A Stylization of Hagiographical Composition in Nikolai Leskov's «Singlethought» (Odnodum) // The Slavic and East European Journal, 1983. Vol. 27 , no. 4, pp. 416-432.

7. Billington J. H. Ikona i topór. Historia kultury rosyjskiej. Tłum. J. Hunia. Kraków, 2008. $777 \mathrm{p}$.

8. Muller de Morogues I. N. S. Leskov: propagandiste religieux et critique de litté rature édifante // Cahiers du monde russe: Russie, Empire russe, Union soviétique, États indépendants. 1996. Vol. 37, no. 4, pp. 381-395. 
Marta Lukashevich

Ph.D in Philology, Research Fellow, Warsaw University

(Warsaw, Poland)

marta.lukaszewicz@uw.edu.pl

\title{
THE BIBLE IN THE STRUCTURE OF N. S. LESKOV'S "THE SINGLETHOUGHT"
}

\begin{abstract}
There are a lot of facts to prove that Nikolai Leskov placed great emphasis on the Bible in his career as a writer. His earlies contributions to newspapers were devoted to the issue of the Bible's accessibility. As a publisher and editor, he did a lot to improve the knowledge of the Bible among the Russian people, viewing this process as a basis for moral education. Leskov's works of fiction often feature biblical quotes, reminiscences and imagery. The objective of our article is to assess the importance of the Bible for the structure of Odnodum (The Singlethought) - a short story Leskov wrote in 1879. Set against other texts of the same author, The Singlethought stands out as a text where the link to the Bible is more accentuated both in form and content. We provide an analysis of how the Bible influenced the personality growth of the protagonist, Alexander Ryzhov, and his behavior models, as well as how the society views him. It is also important to provide the historical context of the discussions of the role of the Bible in the life of the Orthodox community, namely the debates on the Russian Bible Society and the Russian translation of the Bible. Ryzhov's reputation of "an eccentric" and "of doubtful faith" put him in the same class with Leskov's other righteous characters, making this protagonist timeless and important.
\end{abstract}

Keywords: N. S. Leskov, Bible, prophet, yurodivy, Russian Bible Society

\section{References}

1. Gorelov A. A. «Pravedniki» i «pravednichesky» tsikl v tvorcheskoy evolyutsii N. S. Leskova ["Righteous Men" and "Righteous Worldview" Cycle in the Creative Evolution of Nikolai Leskov]. Leskov i russkaya literatura [Leskov and Russian Literature]. Moscow, Nauka Publ., 1988, pp. 39-61.

2. Kadaner O. V. Bibleyskie motivy v antinigilisticheskom romane N. S. Leskova «Na nozhakh» [The Biblical Motifs in the Antinihilist Novel "At Loggerheads" by Nikolai Leskov]. Literatura i khristianstvo [Literature and Christianity]. Belgorod, BelSU Publ., 2000, pp. 68-69.

3. Safran G. Evangel'skiy podtekst i evreyskaya tema vo «Vladychnom sude» N. S. Leskova [Evangelic Subtext and Jewish Theme in Nikolai Leskov's Short Novel "The Lord's Judgement"]. Problemy istoricheskoy poetiki [The Problems of Historical Poetics]. Petrozavodsk, PetrSU Publ., 1998. Vol 5: Evangel'skiy tekst v russkoy literature XVIII-XX vekov: tsitata, reministsentsiya, motiv, syuzhet, zhanr [The Gospel Text in Russian Literature of 18th-20th Centuries: Quotation, Reminiscence, Motif, Plot, Genre]. Issue 2. pp. 462-469.

4. Florovsky G., Archpriest. Puti russkogo bogosloviya [Ways of Russian Theology]. Paris, YMCA-PRESS, 1983. 599 p.

5. Khalizev V., Maiorova O. Leskovskaya kontseptsiya pravednichestva [Nikolai Leskov's Concept of the "Righteous Worldview"]. V mire Leskova [In the World of Nikolai Leskov]. Moscow, Sovetsky pisatel’ Publ., 1983, pp. 196-232.

6. Alissandratos J. A Stylization of Hagiographical Composition in Nikolai Leskov's «Singlethought» (Odnodum). The Slavic and East European Journal, 1983, vol. 27, no. 4 , pp. $416-432$.

7. Billington J. H. Ikona i topór. Historia kultury rosyjskiej (in Polish) [The Icon and the Axe: an Interpretive History of Russian Culture]. Translated by Justyn Hunia. Krakow, 2008. 777 p.

8. Muller de Morogues I. N. S. Leskov: propagandiste religieux et critique de litté rature édifante (in French) [N. S. Leskov: A Religious Propagandist and Critic of Moralistic Literature]. Cahiers du monde russe: Russie, Empire russe, Union soviétique, États indépendants, 1996, vol. 37, no. 4, pp. 381-395.

(C) Лукашевич М., 2012 